\title{
Polymeric polyelectrolytes obtained from renewable sources for biodiesel wastewater treatment by dual-flocculation
}

\author{
E. A. M. Ribeiro ${ }^{1}$, G. Rodrigues Filho ${ }^{1 *}$, N. S. Rozeno ${ }^{1}$, J. M. B. A. Nogueira ${ }^{1}$, M. A. Resende ${ }^{1}$, \\ J. P. Thompson Junior ${ }^{2}$, J. G. Vieira ${ }^{3}$, S. C. Canobre ${ }^{1}$, F. A. Amaral ${ }^{1}$ \\ ${ }^{1}$ Instituto de Química, Universidade Federal de Uberlândia, Campus Santa Mônica, Av. João Naves de Ávila, 2121, Caixa \\ Postal 593, 38.400-902 Uberlândia-MG, Brazil \\ ${ }^{2}$ Universidade São Francisco, Av. São Francisco de Assis, 218, 33495-870 Bragança Paulisa-SP, Brazil \\ ${ }^{3}$ Faculdade de Ciência Integradas do Pontal, Universidade Federal de Uberlândia, Campus do Pontal, Av. José João Dib, \\ 2545, 38302-000 Ituiutaba-MG, Brazil
}

Received 31 October 2016; accepted in revised form 24 January 2017

\begin{abstract}
Biodiesel wastewater generally contains high levels of oils, soaps and glycerol residues. This needs wastewater treatment. In this study, the biodiesel wastewater treatment was tested (industrial wastewater (EFID) and laboratory wastewater (EFLB) from biodiesel) by performing flocculation and dual-flocculation with renewable polymers. Tannin and cationic hemicellulose $(\mathrm{CH})$ were used as cationic flocculant, and cellulose acetate sulfate (CAS) was used as an anionic flocculant. Polyacrylamide (PAM) was used as a reference anionic flocculant for result efficiencies analysis obtained with CAS (renewable source flocculant). The treatment efficacy in wastewater was evaluated by: turbidity removal, sludge volume formed, chemical oxygen demand (COD) and total suspended solids (TSS). The obtained sludge was studied using thermogravimetric analysis (TG). The dual-flocculation application condition of the $25 \%$ proportion of tannin (T) and $75 \%$ proportion of cationic hemicelluloses (i.e., T25/CH75) showed EFLB turbidity removal of $89.1 \%$ and $89.5 \%$ for CAS and PAM additions respectively, and for EFID of $67 \%$ and $41 \%$ for CAS and PAM additions respectively. The dual-flocculation performance suggested that the polyelectrolytes obtained from renewable sources can be used for treating biodiesel wastewater.
\end{abstract}

Keywords: biodegradable polymers, dual-flocculation, biodiesel wastewater, tannin, cellulose acetate sulfate

\section{Introduction}

In recent years, various studies have been carried out for sustainable energy sources that can replace fossil fuels and which do not have a negative impact on the environment. Among the proposals, biofuel production and use is probably the one that has the greatest potential to compensate the current need of fossil fuels. Biofuel can be easily generated from plants biomass resources and organic wastes which are abundant, cheap and renewable [1,2]. Biodiesel has been highlighted due to its chemical and physical properties that resemble to some extent those of diesel, as well as they can be blended with petroleum fuels in various compositions and used in regular engines with little or no modification [1].

Currently, more than $95 \%$ of commercial biodiesel has been produced by transesterification from edible oil (e.g., cottonseed, rapeseed, palm, sunflower and soybean) [3]. Transesterification is the triglycerides reaction with fatty acid alkyl esters and low molecular weight alcohols such as methanol and ethanol with or without a catalyst $[4,5]$.

After the transesterification reaction, biodiesel and glycerol are obtained as main phases. During the biodiesel purification stage glycerol residues, soaps and fatty acids are removed. The large amount of biodiesel

$\overline{{ }^{*} \text { Corresponding author, e-mail: guimes.rodriguesfilho@gmail.com }}$ C BME-PT 
wastewater generated by the washing process - from 20 to $120 \mathrm{~L}$ of water per $100 \mathrm{~L}$ of biodiesel - contains mainly waste sodium or potassium soaps, besides the fatty acids, glycerin, alcohols (methanol or ethanol) and other contaminants, and from the point of view of environmental preservation, it is necessary to adopt treatment for this wastewater $[6,7]$.

Wastewater from the biodiesel production usually has high levels of oil and fat, and low level of nitrogen and phosphorus. This generated wastewater makes the biological treatment of biodiesel residue very difficult. Although membrane bioreactor was effective in treating biodiesel wastewater, a more soluble microbial product during biological treatment could lead to increases in the particle size with irregular shape, resulting in severe membrane fouling [8]. Therefore, physical-chemical methods are often proposed [9].

Typically, coagulation-flocculation process is regarded as one of the most important treatment processes of industrial wastewater [10] and raw water [11] due to its simplicity, effectiveness and low energy consumption.

Coagulation-flocculation process aims at agglomerating the impurities which are fine suspensions [12]. Typical coagulating and flocculant agents are inorganic salts such as $\mathrm{Al}_{2}\left(\mathrm{SO}_{4}\right)_{3}$ or $\mathrm{FeCl}_{3}$ and synthetic polyacrylamides respectively. Aluminum salts are likely to damage the human body undesirably, e.g., in particular the nervous system a scientifically proven fact and has increasingly become a target in medical research world, which requires strict control concerning the presence of metals in both the drinking water and in spring water [13]. Synthetic polymers e.g. polyacrylamide (PAM) - contains some drawbacks originating from the manufacturing process such as: low biodegradability, the potential toxicity of residual monomer, other reagents and by-products that could potentially negatively impact the human health. Thus, in recent years, there has been considerable interest in the natural coagulants development [13].

The use of water soluble polymers as flocculants to control the colloids stability is used in, for instance, conventional water and waste water treatment processes [14]. The main factors of flocs formation are bridging and the surface charge neutralization due to simultaneous polyelectrolyte macromolecules adsorption on the several particles surface. Also flocculation may occur by depletion flocculation or by the combination of these mechanisms [15]. Chen and Wang [16] studied the use of flocculants in singleand dual-chemical conditioning to treat activated sludge (AS). It was observed that the flocculant dosage was lower under dual-chemical conditioning than under single-chemical conditioning. In addition, the flocs/AS aggregates indicate that the treatment forms a larger, more and denser compact structure with the dual-chemical conditioning. The paper here in [15] shows that the use of the flocculation by compositions, based on synthetic and natural polyelectrolyte using an aqueous kaolin dispersion, fosters improvement of floc sedimentation rates as well as the formation of two fold denser floc compared to using individual flocculants. At the study [17] oppositely charged polyelectrolytes were used and stimulated a significant improvement in the particles flocculation and significant turbidity reduction. They also showed that complete colloidal particles neutralization was not required to achieve a satisfactory flocculation performance. Sánchez-Martín et al. [18] reported the potential of natural coagulant for wastewater treatment due to the need to implement new sustainable technologies. Natural organic flocculation based on natural organic polymers such as: starch $[19,20]$, hemicelluloses [21,22], chitosan [23-25], cellulose and its derivatives $[26,27]$ can also be used to complement the traditional coagulants performance, whereas in others cases they can replace them completely. The advantages of these natural polyelectrolytes over the synthetic ones include safety to human health, biodegradability and broader effective dose range for flocculating various colloidal suspensions [13].

The natural polysaccharides modification has been investigated as a way to combine their best attributes with the synthetic polymers properties. Polysaccharides are relatively stable to shear and are biodegradable. However, they have lower efficiency and need to be used at high concentrations [28].

Tannins are plant polyphenolic products. Their natural origin is as plant secondary metabolites, occur in the bark, fruit and leaves [29, 30]. Tannins have been the subject of research that demonstrated their large industrial applications, among them in water treatment [13]. In water treatment cationic tannin is generally used. These are obtained from the chemical reaction that grants the cationic character for the organic matrix material. Thus new features are added, 
such as the coagulation activity, since positively charged products can destabilize anionic colloids when mixed in aqueous solution [31].

The oilseed crop produces lignocellulosic biomass that is generally underutilized, consisting mainly of cellulose, hemicellulose, and lignin. The corresponding percentages by weight can range from $30-50 \%$, $20-40 \%$ and $10-20 \%$, respectively [32]. This biomass without added value shows an emerging opportunity that allows resources reuse, protect the environment and add value to this waste through chemical modification.

Cationic hemicellulose $(\mathrm{CH})$ derivatives generally have high solubility in water, which is an important aspect of polyelectrolyte used for the wastewaters treatment [21, 33]. Landim et al. [21] reported the cationic hemicelluloses synthesis from the corn husk using the 2,3-epoxypropyltrimethylammonium chloride (ETA) and sodium hydroxide as a catalyst in aqueous solution. The authors demonstrate the feasibility of using cationic hemicellulose as coagulation support to replace the commercial polyelectrolyte (polyacrylamide) in the sewage treatment station). Ribeiro et al. [22] used cationic hemicellulose - obtained from corn husk - in association with tannin for the use in wastewater treatment of industrial laundry. The results showed that the association of tannin and cationic hemicellulose was important for turbidity removal higher than $95 \%$ at all investigated $\mathrm{pH}$ range.

Cellulose acetate sulfate (CAS) is a water-soluble polymer, produced from acetylation and sulfation carried out simultaneously and it was first synthesized by Chauvelon et al. [34]. Cellulose derivatives, having strong polyelectrolytes properties, can be prepared by introducing a greater amount of $\mathrm{HOSO}_{2} \mathrm{O}$ substituents into the chain [35]. Grinshpan et al. [35] observed that the cellulose acetate sulfate possessed a unique combination of properties, like an ability to disperse in water spontaneously, forming stable suspensions with narrow particles size distribution. In addition to the structural-mechanical factor and the electrostatic factor of aggregation stability, these chemical characteristics of the cellulose acetate sulfate allowed to recommend them for effective preparations for the contaminated water purification.

In the literature there are many studies regarding the biodiesel wastewater treatment by coagulation-flocculation [9], adsorption [36], flotation by dissolved air [37], electro-coagulation [38, 39], electro-oxidation [40]. However, there are no reports of biodiesel wastewaters treatment by flocculation using only natural flocculants. This study proposes to investigate the efficiency of wastewater biodiesel treatment by flocculation and dual-flocculation using cationic and anionic polymers from renewable resources.

\section{Experimental}

\subsection{Characterization of polymers}

Characterization of polyelectrolyte (cationic hemicelluloses, tannin, cellulose acetate sulfate and polyacrylamide) was evaluated by Fourier transform infrared (FT-IR) spectroscopy and the intrinsic viscosity determination of the polyelectrolyte. A Shimadzu IRPrestige-21 spectrophotometer was used to get FT-IR spectra using a KBr pellets $(1 / 100 \mathrm{w} / \mathrm{w})$, thirtytwo scans were recorded from 4000 to $500 \mathrm{~cm}^{-1}$.

The intrinsic viscosity $\left(\eta_{\text {int }}\right)$ of cationic and anionic polymers were obtained from the solvent flow time of the dilute solutions of the polymers using a viscometer Ostwald [41, 42] kept in a thermostatic bath at $25^{\circ} \mathrm{C}$. Deionized water (common solvent to all polymers) was used for the polymer solutions preparation of $0.005 \mathrm{~mL} \cdot \mathrm{g}^{-1}$. The intrinsic viscosity was determined from the equation proposed by Solomon and Ciuta, which allows to find the intrinsic viscosity by a single point (Equation (1)) [43]:

$\eta_{\text {int }}=\sqrt{\frac{2 \cdot\left(\eta_{\mathrm{sp}}-\ln \eta_{\mathrm{rel}}\right)}{C}}$

where $\eta_{\text {int }}-$ intrinsic viscosity; $\eta_{\mathrm{sp}}-$ specific viscosity $\left(\eta_{\text {sp }}-1\right) ; \eta_{\text {rel }}-$ relative viscosity $(t$ (solution flow time) $/ t_{0}$ (flow time of solvent)); and $C$ - solution concentration.

\subsection{Industrial and laboratory wastewater}

The study was done using two types of biodiesel wastewaters, both produced by transesterification method from vegetable oils. Biodiesel Industrial wastewater (EFID) was produced by company located in Goiás state, Brazil. The biodiesel laboratory wastewater (EFLB) was produced in the Polymer Recycling Laboratory from the Federal University of Uberlândia/MG, Brazil. The biodiesel laboratory wastewater was produced by alkaline transesterification reaction using commercial soy oil, methanol (Vetec) and potassium hydroxide (Synth). In the alkaline transesterification under mechanical stirring, 
the experimental conditions were $1,0 \%(\mathrm{~m} / \mathrm{m})$ of $\mathrm{KOH}$, molar ratio of $1: 6$ oil:alcohol at $45^{\circ} \mathrm{C}$ for $50 \min [44]$.

\subsection{Polyelectrolytes}

Cationic Tannin - Tanfloc SG - used in this study was obtained from TANAC-Brazil. Polyacrylamide (in gel form) - RapFloc 10 - was obtained from Reluz Chemicals Ltd. Cationic hemicellulose and cellulose acetate sulfate were obtained using methods proposed by the Polymer Recycling Laboratory from the Federal University of Uberlândia, Brazil.

The cationic hemicelluloses and cellulose acetate sulfate were produced from the hemicellulose A and cellulose respectively, both extracted from husk peanut (biomass residue) according to the process described by Vieira et al. [45].

\section{Synthesis of cationic hemicellulose}

Cationic hemicelluloses obtained from the hemicellulose A from the husk peanut were converted into cationic hemicelluloses by quaternization with 2,3epoxypropyltrimethylamonium chloride (ETA) in basic medium, according to the process described by Landim et al. [21].

\section{Synthesis of cellulose acetate sulfate}

The CAS produced from the husk peanut cellulose was obtained from acetylation and sulfation. Both reactions were carried out simultaneously in the reaction medium of acetic acid, using acetic anhydride such as acetylating agent and sulfuric acid such as catalyst and sulfation agent, complying with the methodology described by Nascimento et al. [46].

\subsection{Physico-chemical properties}

The jar test experiments were made in equipment from the Policontrol - Brazil and the treatment steps are shown in Figure 1. The raw biodiesel wastewater was demulsified by adding concentrated sulfuric acid (from Vetec) up to $\mathrm{pH} 2$ for oils separation. Reduction of oil and grease were determined gravimetrically by the methods described in Standard Methods,

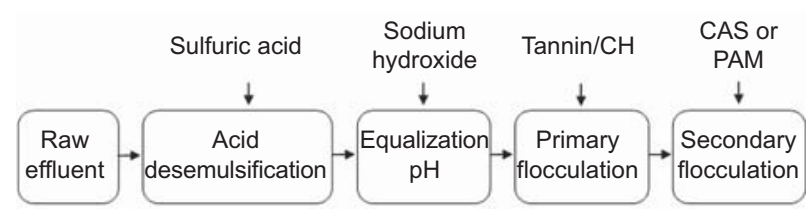

Figure 1. Scheme of step investigated in jar test experiment for biodiesel wastewater treatment $20^{\text {th }}$ ed. [47]. After this step, the equalization $\mathrm{pH}$ of the wastewater was adjusted with stock solution sodium hydroxide 10\% (w/v) (Synth).

Solutions of tannin (T) and cationic hemicellulose were prepared at a concentration of $10 \%(\mathrm{w} / \mathrm{v})$, stirred for $5 \mathrm{~min}$, where the amount of primary flocculant added was determined by monitoring the $\mathrm{pH}$ until the greatest sedimentation rate was obtained. This occurred in equalization at $\mathrm{pH} 12$ and coagulation at $\mathrm{pH}$ 8. The solutions of anionic polymers used as secondary flocculant - polyacrylamide and cellulose acetate sulfate - both were prepared at a concentration of $0.1 \%(\mathrm{w} / \mathrm{v})$, with addition time of $0.2 \mathrm{~min}$ and the system was stirred for another $1 \mathrm{~min}$. After the additions of flocculants the system was allowed to settle for $30 \mathrm{~min}$.

After the sedimentation the turbidity was measured using a Turbidimeter (2100p turbidimeterHach) and the sludge volume formed was calculated by Cones Imhoff ${ }^{\mathbb{B}}$. The sludge was analyzed by thermal stability using Thermogravimetric Analysis (TG) performed in Shimadzu DTG-60H. The heating rate was $10^{\circ} \mathrm{C} \cdot \mathrm{min}^{-1}$ and nitrogen flow was $50 \mathrm{~cm}^{3} \cdot \mathrm{min}^{-1}$. The weight change was recorded in the range of $25-$ $600^{\circ} \mathrm{C}$.

The COD measurements were performed by chemical oxidation of organic matter present in the sample in acid medium, being used sulfuric acid $\left(\mathrm{H}_{2} \mathrm{SO}_{4}\right)$ (excess), potassium dichromate $\left(\mathrm{K}_{2} \mathrm{Cr}_{2} \mathrm{O}_{7}\right)$ as oxidizing agent and silver sulfate $\left(\mathrm{Ag}_{2} \mathrm{SO}_{4}\right)$ as catalyst, described in the Standard Methods, $20^{\text {th }}$ ed. [47]. The total suspended solids were determined gravimetrically by the methods described in Standard Methods, 22 ed. [48].

\section{Results and discussion}

\subsection{Characterization of polymers}

The cationic polyelectrolyte (tannin and cationic hemicelluloses) and anionic polyelectrolyte (cellulose acetate sulfate and polyacrylamide) were studied for the biodiesel wastewater treatment. The materials chemical structures used are shown in Table 1. The corresponding FT-IR values are presented in Figure 2 and Table 2.

FT-IR spectra of tannins have main bands in the main region located in 3415, 1607, 1462 and $1110 \mathrm{~cm}^{-1}$. All the bands are associated with the tannin structure and cationic agent. The absorbance at $1607 \mathrm{~cm}^{-1}$ can be assigned to the aromatic ring attached to the tannin structure. Moreover, the band at $1110 \mathrm{~cm}^{-1}$ is attributed 
Table 1. Chemical structure of the polyelectrolyte used for biodiesel wastewater treatment

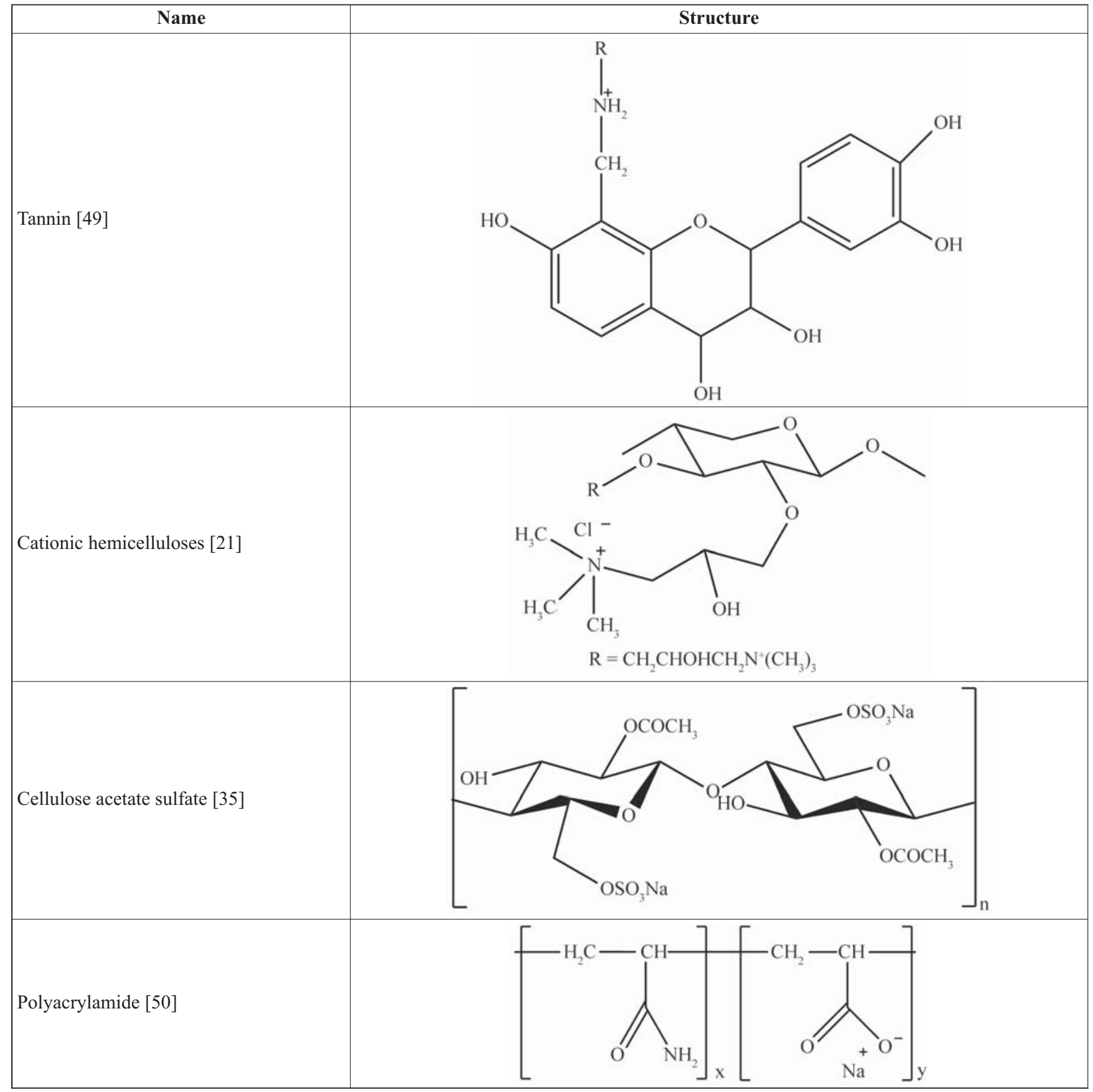

to the $\mathrm{C}-\mathrm{O}$ bond stretching. The absorbance at $3415 \mathrm{~cm}^{-1}$ assigned to the $\mathrm{N}-\mathrm{H}$ bonds stretching vibration in amino groups and the $\mathrm{CH}_{3}$ stretching band at $1462 \mathrm{~cm}^{-1}$. These bands prove the cationic agent incorporation onto the tannin main chain [51].

The FT-IR spectra cationic hemicelluloses showed absorbance at 1048 and $1165 \mathrm{~cm}^{-1}$ referring to the $\mathrm{C}-\mathrm{O}$ and $\mathrm{C}-\mathrm{O}-\mathrm{C}$ stretching of ether groups respectively, corresponding to the hemicelluloses structure quaternization [14]. Furthermore, the symmetric $\mathrm{C}-\mathrm{H}$ vibration band at 2910 and $1426 \mathrm{~cm}^{-1}$ indicates the emerging of $\mathrm{CH}_{3}$ and $\mathrm{C}-\mathrm{C}$ groups in the hemicellulose structure respectively. The intense band at $1624 \mathrm{~cm}^{-1}$ is assigned to absorbed water [52].

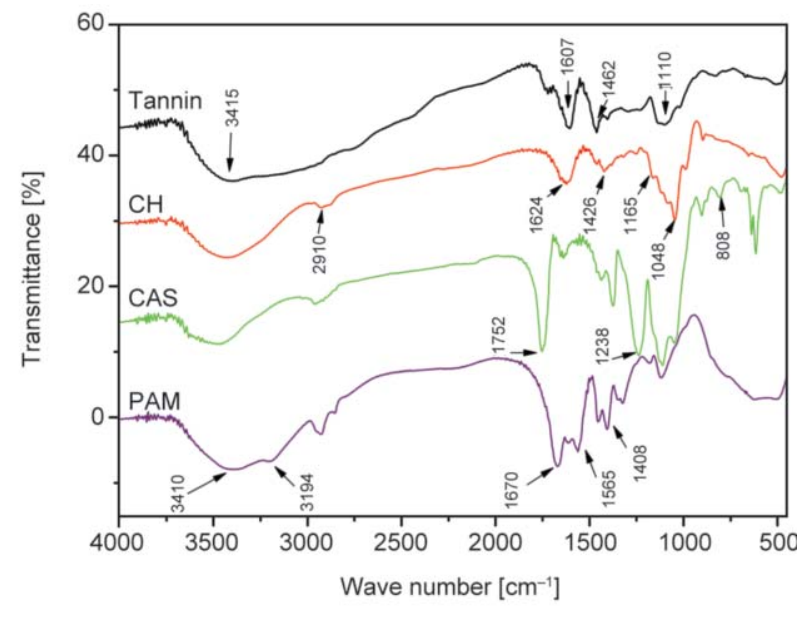

Figure 2. FT-IR spectra of polyelectrolytes 
Table 2. Assignments of the main absorption FT-IR bands $\left[\mathrm{cm}^{-1}\right]$ to the polyelectrolytes tannin, CH, CAS and PAM

\begin{tabular}{|c|c|c|c|c|}
\hline \multicolumn{4}{|c|}{$\begin{array}{c}\text { Peak } \\
{\left[\mathrm{cm}^{-1}\right]}\end{array}$} & \multirow[t]{2}{*}{ Assignment } \\
\hline Tannin & CH & CAS & PAM & \\
\hline \multirow[t]{3}{*}{3415} & 3424 & 3446 & 3410 & Asymmetric $\mathrm{NH}_{2}$ of acrylamide unit and $\mathrm{OH}$ of adsorbed water \\
\hline & & & 3194 & Symmetric $\mathrm{NH}_{2}$ of acrylamide unit \\
\hline & 2910 & 2944 & 2934 & $\mathrm{C}-\mathrm{H}$ and asymmetric $\mathrm{CH}_{3}$ \\
\hline \multirow[t]{2}{*}{1724} & & 1752 & & $\mathrm{C}=\mathrm{O}$ phenolic esters \\
\hline & & & 1670 & $\mathrm{C}=\mathrm{O}$ of acrylamide \\
\hline \multirow[t]{2}{*}{1607} & 1624 & 1630 & & $\mathrm{C}=\mathrm{C}$ aromatic ring \\
\hline & & & 1565 & Asymmetric $\mathrm{COO}^{-}$of Na-acrylate \\
\hline \multirow[t]{5}{*}{1462} & & & & Asymmetric $\mathrm{C}-\mathrm{H}$ deformation \\
\hline & & & 1408 & Symmetric $\mathrm{COO}^{-}$of Na-acrylate/CN of acrylamide \\
\hline & 1426 & 1436 & & $\mathrm{C}=\mathrm{C}$ aromatic ring \\
\hline & & 1373 & 1330 & Asymmetric $\mathrm{CH}_{3}$ \\
\hline & & 1238 & & $\mathrm{~S}=\mathrm{O}$ and $-\mathrm{COSO}_{3}$ of sulfate ester \\
\hline \multirow[t]{3}{*}{1110} & 1165 & 1120 & 1112 & $\mathrm{C}-\mathrm{O}-\mathrm{C}$ asymmetric stretching vibration \\
\hline & 1048 & & & $\mathrm{C}-\mathrm{O}$ stretching vibration \\
\hline & & 808 & & Axial S-O-C deformation \\
\hline
\end{tabular}

The FT-IR spectra of anionic polyelectrolyte CAS showed a characteristic bond stretching of the carbonyl groups at $1752 \mathrm{~cm}^{-1}$, confirming the cellulose acetylation. The sulfate groups incorporation in the glycoside units is proven at the FT-IR spectra by the presence of a band at $1238 \mathrm{~cm}^{-1}$ stretching attributed to sulfate ester, due to the groups $\mathrm{S}=\mathrm{O}$ and $-\mathrm{COSO}_{3}$. The band in the region $808 \mathrm{~cm}^{-1}$ refers to the presence of sulfates groups located at position 6 of the glycoside ring, besides being a characteristic of peak axial deformation of the $\mathrm{S}-\mathrm{O}-\mathrm{C}$ system [46]. The presence of sulfate groups favors the solubility in CAS water. The sulfate groups conferred an increase of the hydrophilic character in the polyelectrolyte and more water solubility [34].

The FT-IR spectra of polyacrylamide, Figure 2, showed a primary absorbance in the region of $3410 \mathrm{~cm}^{-1}$; and a shoulder at $3194 \mathrm{~cm}^{-1}$. These values can be assigned to the asymmetric $\mathrm{NH}_{2}$ and symmetric $\mathrm{NH}_{2}$ vibrations, respectively. The band at $1670 \mathrm{~cm}^{-1}$ corresponds to $\mathrm{C}=\mathrm{O}$ bond stretching characteristics of the acrylamide unit. The bands at 1565 and $1408 \mathrm{~cm}^{-1}$ are due to carboxylate group stretching of acrylate [53].

\subsection{Physico-chemical treatment}

The raw biodiesel wastewater was evaluated using parameters, such as turbidity removal, chemical oxygen demand (COD), total suspended solids (TSS) and $\mathrm{pH}$ as shown in Table 3. The treatment was optimized using EFLB and the best condition was applied to the industrial biodiesel wastewater.
Table 3. Physical and chemical characteristics of raw wastewater

\begin{tabular}{|l|r|r|}
\hline \multicolumn{1}{|c|}{ Parameters } & EFLB & EFID \\
\hline Turbidity $[\mathrm{NTU}]$ & 1100 & 1100 \\
\hline $\mathrm{COD}\left[\mathrm{mg} \mathrm{O}{ }^{-1} \cdot \mathrm{L}^{-1}\right]$ & $>15000$ & $>15000$ \\
\hline $\mathrm{TSS}\left[\mathrm{mg} \cdot \mathrm{L}^{-1}\right]$ & 2400 & 3040 \\
\hline $\mathrm{pH}$ & $5.0-6.5$ & $7.0-9.0$ \\
\hline
\end{tabular}

Acid demulsification was performed to foster the separation of biodiesel and residual oils by acid protonation. The wastewater was acidified by adding sulfuric acid in a range of $\mathrm{pH}$ between 2.0 and 2.5, until the protonation was completed.

Sulfuric acid added to the wastewater promoted the separation in two phases. The lower phase - predominantly aqueous - had a high turbidity, while the higher layer - predominantly oil - had a yellow color similar to biodiesel [40]. The determination of oil and grease for EFLB and EFID after acidification and decanting step (with subsequent phase separation) stimulated a significant oil and biodiesel removal present in the wastewater, from 1000 to $46 \mathrm{mg} \cdot \mathrm{L}^{-1}$ (reduction of $95.4 \%$ ) and $140 \mathrm{mg} \cdot \mathrm{L}^{-1}$ (reduction of 86.0\%) for EFLB and EFID respectively. This result is comparable to those found by Jaruwat et al. [40] where in the acidification step with sulfuric acid and subsequent separation of phases reached a reduction of $87-98 \%$ in the levels of oil and grease from biodiesel wastewater.

After the acid demulsification, the aqueous phase was separated and the $\mathrm{pH}$ adjusted up to 12 with $\mathrm{NaOH}$ $(10 \% \mathrm{w} / \mathrm{v})$. This $\mathrm{pH}$ adjustment was necessary because at lower $\mathrm{pHs}$, coagulation was not obtained, 
suggesting that the addition of electrolytes to wastewater is necessary. According to Ravina and Moramarco [54], the change in ionic concentration favors the double-layer compression around the colloid. Only the double-layer compression is not a treatment technique, but it can be applied together with coagulants-flocculants which favor other interaction mechanisms between particles-flocculants such as load neutralization, bridging and dual-flocculation, among others. The aqueous phase (wastewater) was treated by flocculation and dual-flocculation using polyelectrolytes from renewable resources.

\subsubsection{Determination of flocculation $\mathrm{pH}$ and dosage}

Flocculation $\mathrm{pH}$ was selected to determine the minimum $\mathrm{pH}$ required for floc formation and turbidity removal from the wastewater. The primary flocculant selected for treatment was Tanfloc SG (tannin). To obtain the flocculation $\mathrm{pH}$, only tannin was used to promote the $\mathrm{pH}$ reduction, once that this establishes the relationship of the amount added with the wastewater $\mathrm{pH}$.

The results of turbidity and flocculant dosage as a function of $\mathrm{pH}$ are shown in Figure 3.

In Figure 3 it is observed a $72.7 \%$ turbidity removal for $\mathrm{pH} 9$ and residual turbidity of $300 \pm 5.7 \mathrm{NTU}$, suggesting that the coagulant dosage of $0.8 \mathrm{~g} \cdot \mathrm{L}^{-1}$ was not sufficient for total flocculation. For the range of pH 8 and 7, there was 96.6 and $94.7 \%$ turbidity removal, respectively. The residual turbidity values were $37 \pm 1.8 \mathrm{NTU}(\mathrm{pH} 8)$ and $58 \pm 2.3 \mathrm{NTU}(\mathrm{pH} 7$ ), suggesting that the best flocculant dosage range is from 0.86 to $0.96 \mathrm{~g} \cdot \mathrm{L}^{-1}$ in order to have the lowest turbidity. At $\mathrm{pH} 6$, as dosage is increased $\left(1.19 \mathrm{~g} \cdot \mathrm{L}^{-1}\right)$

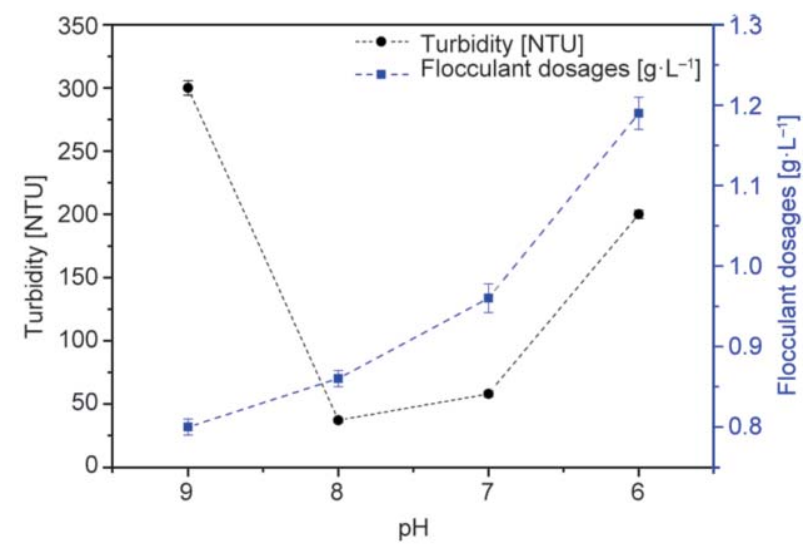

Figure 3. Turbidity $[\mathrm{NTU}]$ and flocculant dosage $\left[\mathrm{g} \cdot \mathrm{L}^{-1}\right]$ as a function of flocculation $\mathrm{pH}$, using tannin in concentration $10 \%(\mathrm{w} / \mathrm{v})$ it is suggested that the colloidal system was restabilized, as there was a decrease in turbidity, and residual turbidity of $200 \pm 3.2 \mathrm{NTU}(81.8 \%)$ was obtained. This observation is according to Lemanowicz et al. [55] because there is an optimal dosage of polymer for which the floc formation occurs effectively.

At higher coagulant concentration, the coagulation was reduced because of steric stabilization, resulting in inhibition of the bridge flocculation mechanism. On the other hand, at a lower flocculant dosage, the opportunity for bridging was also reduced and very small flocs were formed. Another factor influencing the flocculation is charge neutralization, where the oppositely charged polymer adsorbs the particle, reduces the particle charge and destabilizes the suspension [23, 55-57].

\subsubsection{Investigation of the use of cationic hemicellulose associated with tannin}

In order to evaluate the $\mathrm{CH}$ contribution in the wastewater treatment, tests were carried to find the best form of tannin application associated with $\mathrm{CH}$. The studies were done using tannin solutions $(10 \% \mathrm{w} / \mathrm{v})$ and $\mathrm{CH}(10 \% \mathrm{w} / \mathrm{v})$. The application were carried out by adding tannin and cationic hemicelluloses in separate; afterwards, in sequence (i.e., $\mathrm{CH} \rightarrow$ tannin and tannin $\rightarrow \mathrm{CH}$ ) and premix (i.e., solutions in the proportion $50 / 50 \%(\mathrm{v} / \mathrm{v})$ tannin and $\mathrm{CH}$ respectively), in $\mathrm{pH}$. The turbidity and sludge volume formed for the experiments are shown in Table 4.

Cationic hemicelluloses - (b) $\mathrm{CH}$ - applied without being associated with the tannin did not promote wastewater flocculation. When the two polymers were added in sequence - (c) $\mathrm{CH} \rightarrow$ tannin - did not result in sludge removal, obtaining a residual turbidity exceeding 1100 NTU. The addition of tannin followed cationic hemicellulose - (d) Tannin $\rightarrow \mathrm{CH}-$ provided a residual turbidity of $38 \mathrm{NTU}$, and a sludge volume of $194 \mathrm{~cm}^{3}$. These turbidity and sludge

Table 4. Turbidity and sludge volume formed application: tannin $\left(0.86 \mathrm{~g} \cdot \mathrm{L}^{-1}\right)(\mathrm{a})$; cationic hemicellulose $\left(0.86 \mathrm{~g} \cdot \mathrm{L}^{-1}\right)(\mathrm{b})$; in sequence $(\mathrm{c}, \mathrm{d})$ and pre-mixture (e)

\begin{tabular}{|l|c|c|}
\hline \multicolumn{1}{|c|}{ Application } & $\begin{array}{c}\text { Turbidity } \\
{[\text { [NTU] }}\end{array}$ & $\begin{array}{c}\text { Sludge volume formed } \\
{\left[\mathbf{c m}^{\mathbf{3}}\right]}\end{array}$ \\
\hline (a) Tannin & $30 \pm 2.0$ & $196 \pm 2.4$ \\
\hline (b) $\mathrm{CH}$ & $>1100$ & - \\
\hline (c) $\mathrm{CH} \rightarrow$ Tannin & $>1100$ & - \\
\hline (d) Tannin $\rightarrow \mathrm{CH}$ & $38 \pm 1.8$ & $194 \pm 2.8$ \\
\hline (e) $\mathrm{T} / \mathrm{CH}$ & $27 \pm 1.9$ & $101 \pm 2.3$ \\
\hline
\end{tabular}


volume values were similar to the treatment with tannin applied in the same dosage, thus no influence of cationic hemicellulose flocculation was observed. The treatment provided a residual turbidity of 27 NTU and sludge volume of $101 \mathrm{~cm}^{3}$, when the polymers were applied in the form of a premix (e) (i.e., prepared beforehand). Turbidity similar to the treatment with tannin (30 NTU), suggests that there was no significant influence of $\mathrm{CH}$ on the turbidity removal. However, it was observed that there was influence of $\mathrm{CH}$ on the flocculation, for compact flocs formation by adsorption, since there was a reduction of $51 \%$ in the sludge volume formed compared with treatment with tannin.

The use of cationic hemicellulose as coagulation support (premix of tannin and $\mathrm{CH}$ ) was also favorable as a test in wastewaters from industrial laundries performed by Ribeiro et al. [22] who proposed that the associated action promoted a probable interaction between tannin and $\mathrm{CH}$ (acids and bases Lewis, or hydrogen bonds) which resulted in a synergistic effect in the coagulation process. Somasundaran et al. [58] suggested that the modified polysaccharide adsorption in particles can be primarily made by hydrogen bonds and hydrophobic interactions between modified polysaccharides and particle surfaces. Besides, it was also perceived that there occurred the formation of particle by polysaccharide interaction (tannin and $\mathrm{CH}$ ) because the reduction in the sludge volume formed.

\subsection{Dual-flocculation effect}

The addition of cationic polymers, tannin and $\mathrm{CH}$ $(\mathrm{T} / \mathrm{CH})$, were responsible for the primary wastewater flocculation. Anionic polymers were added (PAM and CAS) used as secondary flocculants, at a concentration of $0.1 \%(\mathrm{w} / \mathrm{v})$ to the medium, aiming to get a solid-liquid separation more efficient in the turbidity removal and sludge volume formed.

\subsubsection{Dual-flocculation effect on the turbidity removal}

The effects of both anionic polyelectrolytes, CAS and PAM, were performed by calculation of the turbidity removal using as reference the treatment with $\mathrm{T} / \mathrm{CH}$. Figure 4 shows the anionic polymers effectiveness calculated by Equation (2). Thus, one can get a sense of the real contribution of removing turbidity caused by the use of anionic polyelectrolyte.

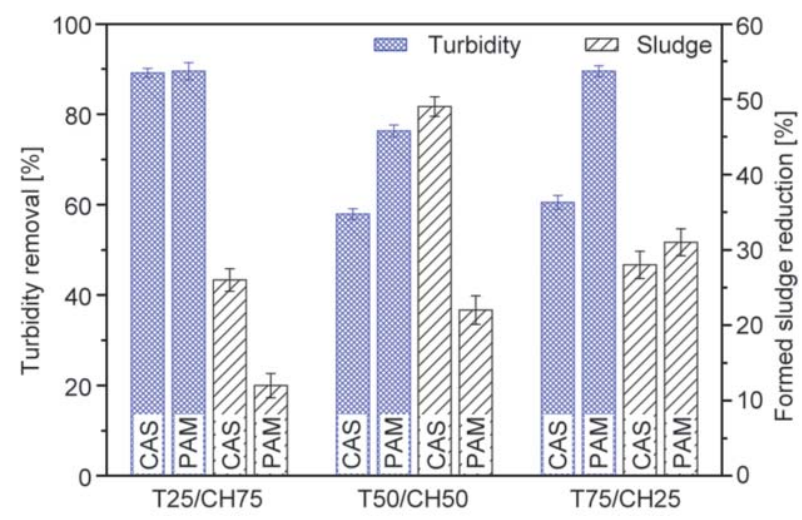

Figure 4. Turbidity removal and formed sludge reduction for EFLB after application of CAS and PAM in different proportions of coagulants

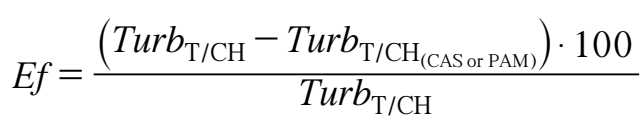

where $\operatorname{Turb}_{\mathrm{T} / \mathrm{CH}}-$ wastewater turbidity after applying primary flocculant; Turb $_{\mathrm{T} / \mathrm{CH}}$ (CAS or PAM) $_{\text {PAstewater }}$ turbidity after applying primary and secondary flocculants.

For all proportions of the primary flocculants $-\mathrm{T} / \mathrm{CH}$ - shown in Figure 4, it was verified that the CAS and PAM application improved turbidity. This suggests that application of oppositely charged polyelectrolyte in treatment assists in the turbidity removal, since oppositely charged polymers adsorb on the particle, reducing the particle charge, destabilizing the suspension [56].

It can be seen that the best efficiency CAS occurred in the ratio $\mathrm{T} 25 / \mathrm{CH} 75$, whose reduction was approximately $89 \%$. The commercial polymer reference PAM - presented its greater efficiency for sample $\mathrm{T} 25 / \mathrm{CH} 75$ and $\mathrm{T} 75 / \mathrm{CH} 25$, of $89.5 \%$ for both, similar to the CAS efficiency. As the highest turbidity removal was obtained for the ratio $\mathrm{T} 25 / \mathrm{CH} 75$, for both anionic polymers, this ratio was chosen for further testing with EFID wastewater.

The behavior of the dual-flocculation system was investigated with regard to EFID wastewater. Table 5 shows the turbidity efficiency removal for samples T25/CH75-CAS and T25/CH75-PAM of $67 \%$ and $41 \%$ respectively.

Treatment with cationic coagulants promoted a significant reduction in turbidity in both wastewaters. However, residual turbidity still has relevant values around 30 to $40 \mathrm{NTU}$ and 45 to $56 \mathrm{NTU}$ for EFLB and EFID wastewaters, respectively. With the application of the dual-flocculation (i.e., opposite charge 
Table 5. Turbidity removal and formed sludge reduction for EFLB and EFID after application CAS and PAM in the proportion $\mathrm{T} 25 / \mathrm{CH} 75$

\begin{tabular}{|l|c|c|c|c|c|}
\hline \multirow{2}{*}{} & & \multicolumn{2}{|c|}{$\begin{array}{c}\text { EFLB } \\
\text { [efficiency \%] }\end{array}$} & \multicolumn{2}{c|}{$\begin{array}{c}\text { EFID } \\
\text { [efficiency \%] }\end{array}$} \\
\cline { 2 - 6 } & T/CH & CAS & PAM & CAS & PAM \\
\hline Turbidity removal & T25/CH75 & $89.1 \pm 1.0$ & $89.5 \pm 1.9$ & $67 \pm 2.2$ & $41 \pm 2.4$ \\
\hline Formed sludge reduction & T25/CH75 & $26 \pm 1.5$ & $12 \pm 1.6$ & $14 \pm 2.5$ & $11 \pm 2.6$ \\
\hline
\end{tabular}

polymer) the CAS and PAM adsorption in floc structure promotes a residual turbidity reduction. The residual turbidity for EFLB was from 3 to 8 NTU and for EFID wastewater was from 14 to 20 NTU. The addition of CAS and PAM (commercial polymer), had the same effect on the turbidity reduction, since the residual turbidities were similar. These results suggest that the renewable CAS source could be comparable to the PAM as a flocculant agent.

\subsubsection{Dual-flocculation effect of the sludge volume reduction}

The values obtained for the sludge volume reduction (after 30 min sedimentation) for samples $\mathrm{T} / \mathrm{CH}$ in different proportions with the addition of flocculant, CAS and PAM, are shown in Figure 4 and Table 5. With the application of the flocculation, there was an increase in the sedimentation efficiency. In the wastewater treatment, the addition of the polymer first is proposed to serve as an 'anchor' for the second polymer adsorption. The initial addition of the polymer alone produces primary flocs that grow in binary flocs after the second polymer addition [56].

It has been proposed that lower molecular weight polymers tend to adsorb and neutralize oppositely charged particles. While larger molecular weight polymers can lead to the bridging flocculation. In these cases, segments of a single polymer chain are bound to more than one particle, thus binding the particles together which creates larger flocs [24]. According to Shak and $\mathrm{Wu}$ [59], an improvement of the size and settling flocs rate could be attributable to the enhanced bridging and charge neutralization mechanism (porous flocs) owing to the synergy between two flocculants.

The effect of molecular weight can be measured by the intrinsic viscosities of the polymers shown in Table 6.

CAS has a lower intrinsic viscosity of $8.17 \mathrm{~mL} \cdot \mathrm{g}^{-1}$ compared with PAM. It was observed that the CAS addition to the system, promoted the formation of smaller floc, justifying the sludge volume reduction for the sample T25/CH75. Samples T50/CH50-CAS
Table 6. Intrinsic viscosity of tannin, $\mathrm{CH}, \mathrm{CAS}$ and PAM

\begin{tabular}{|l|c|}
\hline \multicolumn{1}{|c|}{ Polymers } & $\begin{array}{c}\boldsymbol{\eta}_{\text {int }} \\
{\left[\mathbf{m L} \cdot \mathbf{g}^{-1}\right]}\end{array}$ \\
\hline Tannin & 6.67 \\
\hline CH & 8.06 \\
\hline CAS & 8.17 \\
\hline PAM & 22.71 \\
\hline
\end{tabular}

and T75/CH25-CAS, with 49 and 28\% efficiency respectively, when analyzed concomitantly with the turbidity removal, indicated that the higher reduction in the sludge volume is caused by a lower turbidity removal. As the turbidity removal is lower, it also gets a lower sludge volume thereby increasing the efficiency.

PAM has a high value of intrinsic viscosity, $22.71 \mathrm{~mL} \cdot \mathrm{g}^{-1}$, produced larger binary flocs, thus it was possible to observe from the formed sludge volume a greater efficiency of $31 \%$, for the sample T $75 /$ $\mathrm{CH} 25$, suggesting that flocculant has greater interaction with the primary floc already formed, when a lower concentration of $\mathrm{CH}$ was used in the medium. However, as shown in the results aforementioned, the $\mathrm{CH}$ addition is necessary for the treatment, because it promotes a greater reduction of sludge volume compared only with the application of tannin without the presence of $\mathrm{CH}$ and contributed for decreasing the thermal stability of the formed sludge, favoring its degradation (Figure 5).

The EFID wastewater presented 14 and $11 \%$ efficiency for samples T25/CH75-CAS and T25/CH75PAM respectively. The sludge reduction efficiency was not so expressive. These lower values can be assigned to the higher quantity of TSS the raw industrial wastewater - EFID (Table 3) - which resulted in a higher sludge volume. However, the residual turbidity value from 15 to 20 NTU indicated that flocculation was efficient.

\subsubsection{Thermal gravimetric analysis (TG) of sludge}

Figure 5 shows the thermogravimetric analysis (TG) of sludge obtained from the biodiesel wastewater treatment to the ratio (T25/CH75). The effect of 


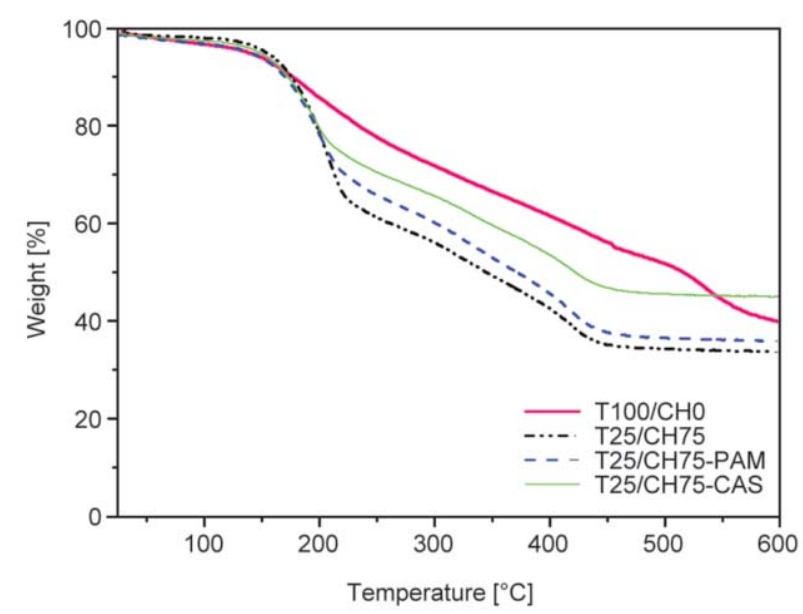

Figure 5. Thermograms of T100/CH0, T25/CH75, T25/CH75$\mathrm{CAS}$ and $\mathrm{T} 25 / \mathrm{CH} 75-\mathrm{PAM}$ in the range of 25 $600^{\circ} \mathrm{C}$ and the heating rate was $10^{\circ} \mathrm{C} \cdot \mathrm{min}^{-1}$ in nitrogen flow

adding cationic hemicelluloses and flocculant during sludge formation was analyzed.

The effect of adding cationic hemicelluloses to the treatment was examined by the sludge thermogravimetric analysis. The sludge thermal stability obtained after treatment is shown in Figure 5. As observed, there was slight weight loss attributed to the water desorption at $145^{\circ} \mathrm{C}$ for all sludges, with loss of 6.0, 4.0, 5.0 and $6.0 \%$ for sample $\mathrm{T} 100 / \mathrm{CH} 0, \mathrm{~T} 25 / \mathrm{CH} 75$, T25/CH75-CAS and T25/CH75-PAM respectively. Comparing the sample $\mathrm{T} 100 / \mathrm{CH} 0$ and other samples - when the $\mathrm{CH}$ was used as coagulation aid T25/CH75, T25/CH75-CAS and T25/CH75-PAM, it was observed that the $\mathrm{CH}$ addition changed the sludge decomposition temperature. In the range from 145 to $510^{\circ} \mathrm{C}$ for sample $\mathrm{T} 100 / \mathrm{CH} 0$ curve there was a higher weight loss, of $44.0 \%$, attributed to the material degradation and between 510 and $600{ }^{\circ} \mathrm{C}$ with weight loss of $10 \%$, attributed to the carbonization of degraded products.

The sample T25/CH75 showed higher weight loss due to degradation in two stages, the range from 145 to $220^{\circ} \mathrm{C}$, at $30 \%$ weight losses, and from 223 to $442{ }^{\circ} \mathrm{C}$, at $30.5 \%$ weight losses. In the range from 442 to $600{ }^{\circ} \mathrm{C}$ the weight loss is only $1.5 \%$ attributed to carbonization of degrades products.

The curves T25/CH75-CAS and T25/CH75-PAM corresponding to the sludge with application of tannin and $\mathrm{CH}$ coagulants and the flocculants $\mathrm{CAS}$ and PAM respectively. The weight loss due to the material degradation occurs at the range from 145 to $208^{\circ} \mathrm{C}$, with $18.5 \%$ and 208 to $450{ }^{\circ} \mathrm{C}$, at $30 \%$ weight losses, for sample T25/CH75-CAS. For the sample
T25/CH75-PAM the degradation occurs within the range from 145 to $214{ }^{\circ} \mathrm{C}$, at $22 \%$, and 214 to $445^{\circ} \mathrm{C}$, with $34 \%$ of weight losses. The last event occurs at $600{ }^{\circ} \mathrm{C}$ with a weight loss of 1.5 and $2 \%$ for samples T25/CH75-CAS and T25/CH75-PAM respectively. Therefore, the purpose to use the cationic hemicellulose as coagulation aid helps both the sludge volume reduction and decrease the sludge decomposition temperature, thus making it more prone to further degradation. The hemicelluloses addition in the treatment fosters a decrease in the sludge decomposition temperature probably due to the higher amount used when compared to the other flocculants. It assists in the stimulation of greater flocs compactness, as well as to provide weak interactions of Van der Waals, compared to the electrostatic forces caused by the tannin molecules. The use of CAS and PAM did not significantly alter the sludge degradation range, but it can be seen that there is an increase in the residual sludge fraction after flocculants addition.

\subsubsection{Dual-flocculation effect on COD and TSS}

The effect on COD and TSS in treatment with the sample T25/CH75, after adding CAS and PAM, were calculated in relation to the raw wastewater. These values are shown in Figure 6 for EFLB and EFID. As it can be seen in Figure 6, the anionic polyelectrolyte addition resulted in a greater reduction of COD for EFID wastewater, with residual COD of 34 and $29 \mathrm{mg} \mathrm{O}_{2} \cdot \mathrm{L}^{-1}$ for the T25/CH75-CAS and T25/CH75PAM samples, respectively. For EFLB the residual COD was 184 and $118 \mathrm{mg} \mathrm{O}_{2} \cdot \mathrm{L}^{-1}$ for the samples T25/CH75-CAS and T25/CH75-PAM, respectively. This fact can be attributed to dependence of the flocculation efficiency with the initial concentration of suspended solids from wastewater. As the residual COD was still high particularly for EFLB, the treatment could remove efficiently the compounds resistant to biological degradation, e.g., glycerol and methanol which are the main components present in the biodiesel wastewater [60].

The EFLB wastewater exhibited residual TSS values 43 and $27\left(\mathrm{mg} \cdot \mathrm{L}^{-1}\right)$ for the samples T25/CH75-CAS and T25/CH75-PAM, respectively and EFID wastewater of 25 and $21 \mathrm{mg} \mathrm{O}_{2} \cdot \mathrm{L}^{-1}$ for the samples T25/ CH75-CAS and T25/CH75-PAM, respectively. The residual TSS values for EFLB and EFID confirm that trends are similar to the turbidity removal. This suggests that application of oppositely charged polyelectrolyte in treatment assists in the TSS removal. 

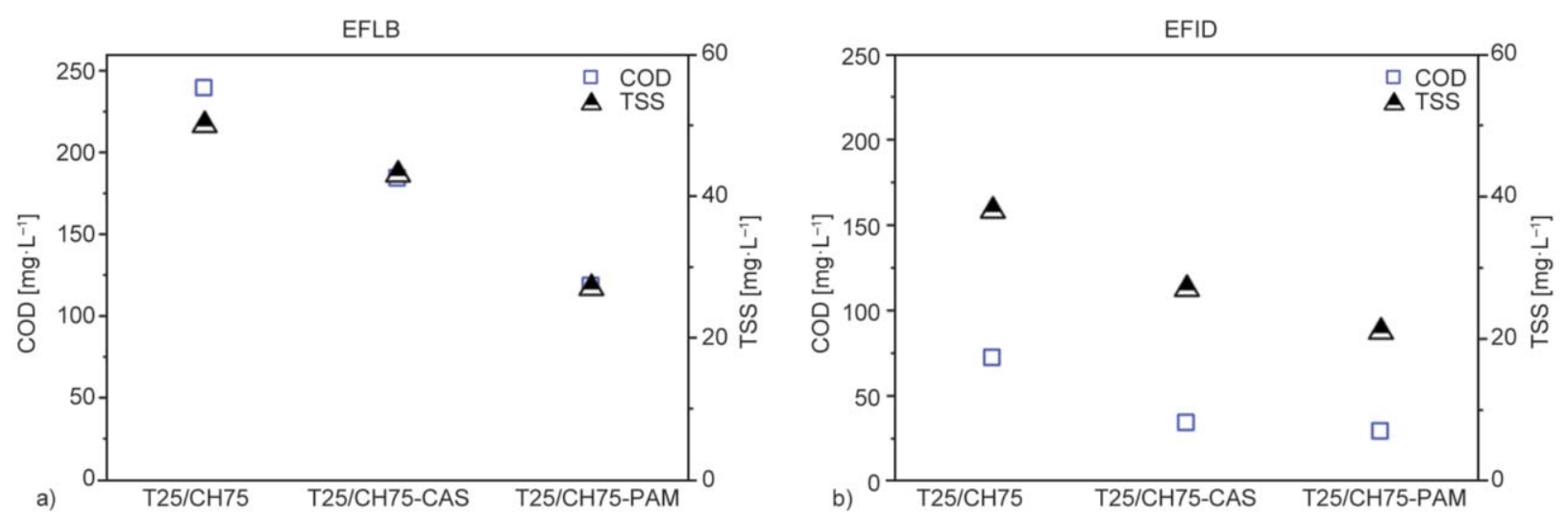

Figure 6. COD and TSS $\left[\mathrm{mg} \cdot \mathrm{L}^{-1}\right]$ values for EFLB (a) and EFID (b) in the proportion of T25/CH75, T25/CH75-CAS and T25/CH75-PAM

Table 7 shows some comparative studies for the biodiesel wastewater treatment with COD, TSS and their removal results. It can be seen that treatment with polymers from renewable sources was equally efficient and in some cases with greater reductions. Once all the conditions tested for both wastewaters obtained COD and TSS reduction above $98 \%$, this suggests that these materials are promising as coagulants in treating this type of wastewater.

Based on the turbidity removal, sludge volume reduction, TSS and COD efficiency, and taking into account the anionic flocculant performance, it was revealed that there was positive contribution on the use of dual-flocculation system. Furthermore, due to the high efficiencies, there was no significant influence of the intrinsic viscosities in the coagulationflocculation system of the anionic polyelectrolyte studied, since the low intrinsic viscosity CAS exhibited behavior comparable to that of high intrinsic viscosity materials (PAM) for biodiesel wastewaters treatment.

\section{Conclusions}

The results suggest that industrial wastewater (EFID) and laboratory wastewater (EFLB) from biodiesel treatment may be performed using renewable polymers. The optimized condition of tannin (T) and cationic hemicellulose $(\mathrm{CH})$ was established using $25 \%$ of tannin and $75 \%$ of $\mathrm{CH}$ (i.e., $\mathrm{T} 25 / \mathrm{CH} 75$ ) for both wastewaters. As this was the condition which exhibited the highest turbidity removal when applied concomitantly with the flocculants cellulose acetate sulfate (CAS) and synthetic polyacrylamide (PAM) commercial.

Tannin was used as the primary coagulant and responsible for producing primary flocs. $\mathrm{CH}$ was used as a coagulating assistant and contributed to the treatment in the reduction of the sludge volume, compared with the addition of only tannin - without the presence of $\mathrm{CH}$ - and decreased thermal stability of the formed sludge, favoring the degradation.

The anionic polymer addition (CAS and PAM) was responsible for the growth of the primary flocs and

Table 7. References of biodiesel wastewater treatment studies

\begin{tabular}{|c|c|c|c|c|c|}
\hline References & Coagulation/flocculation & $\begin{array}{c}\text { COD } \\
{\left[\mathrm{mg} \cdot \mathbf{L}^{-1}\right]}\end{array}$ & \begin{tabular}{|c|} 
Removal \\
{$[\%]$}
\end{tabular} & $\begin{array}{c}\text { SS and TSS } \\
{\left[\mathrm{mg} \cdot \mathrm{L}^{-1}\right]}\end{array}$ & $\begin{array}{c}\text { Removal } \\
{[\%]}\end{array}$ \\
\hline Xie et al. ${ }^{\text {a }}[61]$ & Cationic polyamide and polyaluminum chloride & 23311 & 96.2 & 118 & 98.1 \\
\hline $\begin{array}{l}\text { Rattanapan et } \\
\text { al. } .^{\text {b }} \text { [37] }\end{array}$ & Alum, polyaluminum chloride and ferric chloride & $10000-20000$ & $80.0-90.0$ & $<15$ & $98.0-100$ \\
\hline $\begin{array}{l}\text { Pitakpoolsil and } \\
\text { Hunsom }^{c} \text { [36] }\end{array}$ & Chitosan floc & $1714-3822$ & 90.0 & $50-90$ & 93.0 \\
\hline The author $^{\mathrm{d}}$ & EFLB: tannin, cationic hemicellulose, cellulose acetate sulfate & 184 & 98.7 & 43 & 98.2 \\
\hline The author ${ }^{\mathrm{d}}$ & EFLB: tannin, cationic hemicellulose, polyacrylamide & 118 & 99.2 & 27 & 98.8 \\
\hline The author $^{\mathrm{d}}$ & EFID: tannin, cationic hemicellulose, cellulose acetate sulfate & 34 & 99.7 & 27 & 99.1 \\
\hline The author $^{\mathrm{d}}$ & EFID: tannin, cationic hemicellulose, polyacrylamide & 29 & 99.8 & 21 & 98.8 \\
\hline
\end{tabular}

${ }^{\mathrm{a} C o a g u l a t i o n-F l o c c u l a t i o n}$

${ }^{\mathrm{b}}$ Flotation by dissolved air

${ }^{\mathrm{c} A d s o r p t i o n}$

${ }^{\mathrm{d}}$ Dual-flocculation 
for the binary flocs production. This improved wastewater quality, reducing the turbidity range from 30 to 40 for 3 to 8 NTU for EFLB andfrom 45 to 56 for 14 to 20 NTU for EFID. In addition, they provided a reduction (>98\%) in chemical oxygen demand (COD) and total suspended solids (TSS). Thus, these renewable sources of polyelectrolytes can be used for treating biodiesel wastewater due to the high turbidity efficiency, COD and TSS removal.

\section{Acknowledgements}

The authors acknowledge to FAPEMIG grant CEX-APQ 01128-13. Ribeiro thank FAPEMIG (APQ- 02249-14 and APQ- 03219-14) for their scholarships and financial support, CAPES for 'Portal Periódicos', RQMG (Rede Mineira de Química) and PROAP.

\section{References}

[1] Akhlaghi S., Gedde U. W., Hedenqvist M. S., Braña M. T. C., Bellander M.: Deterioration of automotive rubbers in liquid biofuels: A review. Renewable and Sustainable Energy Reviews, 43, 1238-1248 (2015). https://doi.org/10.1016/j.rser.2014.11.096

[2] Azwar M. Y., Hussain M. A., Abdul-Wahab A. K.: Development of biohydrogen production by photobiological, fermentation and electrochemical processes: A review. Renewable and Sustainable Energy Reviews, 31, 158-173 (2014).

https://doi.org/10.1016/j.rser.2013.11.022

[3] Onukwuli D. O., Emembolu L. N., Ude C. N., Aliozo S. O., Menkiti M. C.: Optimization of biodiesel production from refined cotton seed oil and its characterization. Egyptian Journal Petroleum, in press (2016). https://doi.org/10.1016/j.ejpe.2016.02.001

[4] Atadashi I. M., Aroua M. K., Abdul Aziz A. R., Sulaiman N. M. N.: The effects of water on biodiesel production and refining technologies: A review. Renewable and Sustainable Energy Reviews, 16, 3456-3470 (2012). https://doi.org/10.1016/j.rser.2012.03.004

[5] Mostafaei M., Ghobadian B., Barzegar M., Banakar A.: Optimization of ultrasonic assisted continuous production of biodiesel using response surface methodology. Ultrasonics Sonochemistry, 27, 54-61 (2015).

https://doi.org/10.1016/j.ultsonch.2015.04.036

[6] Noureddini H.: System and process for producing fuel with reduced viscosity and a cloud point below thirtytwo (32) degrees Fahrenheit. U.S. Patent 6174501, USA (2001).

[7] Palomino-Romero J. A., Leite O. M., Eguiluz K. I. B., Salazar-Banda G. R., Silva D. P., Cavalcanti E. B.: Treatments of the effluents generated in the biodiesel production (in Portugese). Química Nova, 2, 367-378 (2012).

https://doi.org/10.1590/S0100-40422012000200025
[8] Khan Y., Yamsaengsung R., Chetpattananondh P., Khongnakorn W.: Treatment of wastewater from biodiesel plants using microbiological reactor technology. International Journal of Environmental Science and Technology, 12, 297-306 (2015).

https://doi.org/10.1007/s13762-014-0501-7

[9] Daud Z., Awang H., Latif A. A. A., Nasir N., Ridzuan M. B., Ahmad Z.: Suspended solid, color, COD and oil and grease removal from biodiesel wastewater by coagulation and flocculation processes. Procedia - Social and Behavioral Sciences, 195, 2407-2411 (2015).

https://doi.org/10.1016/j.sbspro.2015.06.234

[10] Teh C. Y., Budiman P. M., Shak K. P. Y., Wu T. Y.: Recent advancement of coagulation-flocculation and its application in wastewater treatment. Industrial and Engineering Chemistry Research, 55, 4363-4389 (2016). https://doi.org/10.1021/acs.iecr.5b04703

[11] Teh C. Y., Wu T. Y.: The potential use of natural coagulants and flocculants in the treatment of urban waters. Chemical Engineering Transactions, 39, 1603-1608 (2014). https://doi.org/10.3303/CET1439268

[12] Tchobanoglous G., Burton F. L., Stensel H. D.: Wastewater engineering treatment and reuse. McGraw-Hill, Boston (2003).

[13] Özacar M., Şengil I. A.: Evaluation of tannin biopolymer as a coagulant aid for coagulation of colloidal particles. Colloids and Surfaces A: Physicochemical and Engineering Aspects, 229, 85-96 (2003).

https://doi.org/10.1016/j.colsurfa.2003.07.006

[14] Feng L., Stuart M. C., Adachi Y.: Dynamics of polyelectrolyte adsorption and colloidal flocculation upon mixing studied using mono-dispersed polystyrene latex particles. Advances in Colloid and Interface Science, 226, 101-114 (2015). https://doi.org/10.1016/j.cis.2015.09.004

[15] Dryabina S., Fotina K., Navrotskii A., Novakov I.: The flocculation of kaolin aqueous dispersion by two cationic polyelectrolytes. Colloids and Surfaces A: Physicochemical and Engineering Aspects, 515, 12-21 (2017). https://doi.org/10.1016/j.colsurfa.2016.11.055

[16] Chen Q., Wang Y.: Influence of single- and dual-flocculant conditioning on the geometric morphology and internal structure of activated sludge. Powder Technology, 270, 1-9 (2015). https://doi.org/10.1016/j.powtec.2014.10.002

[17] Sang Y., Xiao H.: Clay flocculation improved by cationic poly(vinyl alcohol)/anionic polymer dual-component system. Journal of Colloid and Interface Science, 326, 420-425 (2008). https://doi.org/10.1016/j.jcis.2008.06.058

[18] Sánchez-Martín J., González-Velasco M., BeltránHeredia J.: Surface water treatment with tannin-based coagulants from Quebracho (Schinopsis balansae). Chemical Engineering Journal, 165, 851-858 (2010). https://doi.org/10.1016/j.cej.2010.10.030 
[19] Teh C. Y., Wu T. Y., Juan J. C.: Potential use of rice starch in coagulation-flocculation process of agro-industrial wastewater: Treatment performance and flocs characterization. Ecological Engineering, 71, 509-519 (2014).

https://doi.org/10.1016/j.ecoleng.2014.07.005

[20] Teh C. Y., Wu T. Y., Juan J. C.: Optimization of agroindustrial wastewater treatment using unmodified rice starch as a natural coagulant. Industrial Crops and Products, 56, 17-26 (2014).

https://doi.org/10.1016/j.indcrop.2014.02.018

[21] Landim A. S., Rodrigues Filho G., Sousa R. M. F., Ribeiro E. A. M., de Souza F. R. B., Vieira J. G., Assunção R. M. N., Cerqueira D. A.: Application of cationic hemicelluloses produced from corn husk as polyelectrolytes in sewage treatment. Polímeros, 23, 468-472 (2013).

https://doi.org/10.4322/polimeros.2013.054

[22] Ribeiro E. A. M., Souza F. R. B., Amaral F. A., Rodrigues Filho G., Sousa R. M. F., Vieira J. G., Costa T. F., Thompson Junior J. P., Assunção R. M. N., Canobre S. C.: Utilization of cationic hemicelluloses, obtained from the corn husk, in association with tannin for use in wastewater treatment of industrial laundry (in Portugese). Química Nova, 40, 17-24 (2017).

https://doi.org/10.21577/0100-4042.20160147

[23] Renault F., Sancey B., Badot P-M., Crini G.: Chitosan for coagulation/flocculation processes - An eco-friendly approach. European Polymer Journal, 45, 1337-1348 (2009).

https://doi.org/10.1016/j.eurpolymj.2008.12.027

[24] Rojas-Reyna R., Schwarz S., Heinrich G., Petzold G., Schütze S., Bohrisch J.: Flocculation efficiency of modified water soluble chitosan versus commonly used commercial polyelectrolytes. Carbohydrate Polymers, 81, 317-322 (2010).

https://doi.org/10.1016/j.carbpol.2010.02.010

[25] Li J., Jiao S., Zhong L., Pan J., Ma Q.: Optimizing coagulation and flocculation process for kaolinite suspension with chitosan. Colloids and Surfaces A: Physicochemical and Engineering Aspects, 428, 100-110 (2013). https://doi.org/10.1016/j.colsurfa.2013.03.034

[26] Khiari R., Dridi-Dhaouadi S., Aguir C., Mhenni M. F.: Experimental evaluation of eco-friendly flocculants prepared from date palm rachis. Journal of Environmental Sciences, 22, 1539-1543 (2010).

https://doi.org/10.1016/S1001-0742(09)60286-2

[27] Suopajärvi T., Liimatainen H., Hormi O., Niinimäki J.: Coagulation-flocculation treatment of municipal wastewater based on anionized nanocellulose. Chemical Engineering Journal, 231, 59-67 (2013). https://doi.org/10.1016/j.cej.2013.07.010

[28] Bolto B., Gregory J.: Organic polyelectrolytes in water treatment. Water Research, 41, 2301-2324 (2007). https://doi.org/10.1016/j.watres.2007.03.012
[29] Beltrán-Heredia J., Sánches-Martín J., Gómez-Muñoz M. C.: New coagulant agents from tannin extracts: Preliminary optimisation studies. Chemical Engineering Journal, 162, 1019-1025 (2010).

https://doi.org/10.1016/j.cej.2010.07.011

[30] Sánches-Martín J., Beltrán-Heredia J., Gibello-Pérez P.: Adsorbent biopolymers from tannin extracts for water treatment. Chemical Engineering Journal, 168, 12411247 (2011).

https://doi.org/10.1016/j.cej.2011.02.022

[31] Beltrán-Heredia J., Sánchez-Martín J., Dávila-Acedo M. A.: Optimization of the synthesis of a new coagulant from a tannin extract. Journal of Hazardous Materials, 186, 1704-1712 (2011). https://doi.org/10.1016/j.jhazmat.2010.12.075

[32] Patel M., Kumar A.: Production of renewable diesel through the hydroprocessing of lignocellulosic biomass-derived bio-oil: A review. Renewable and Sustainable Energy Reviews, 58, 1293-1307 (2016).

https://doi.org/10.1016/j.rser.2015.12.146

[33] Ren J. L., Sun R. C., Liu C. F., Chao Z. Y., Luo W.: Twostep preparation and thermal characterization of cationic 2-hydroxypropyltrimethylammonium chloride hemicellulose polymers from sugarcane bagasse. Polymer Degradation and Stability, 91, 2579-2587 (2006). https://doi.org/10.1016/j.polymdegradstab.2006.05.008

[34] Chauvelon G., Buléon A., Thibault J-F., Saulnier L.: Preparation of sulfoacetate derivatives of cellulose by direct esterification. Carbohydrate Research, 338, 743750 (2003).

https://doi.org/10.1016/S0008-6215(03)00008-9

[35] Grinshpan D. D., Savitskaya T. A., Tsygankova N. G., Makarevich S. E., Tretsiakova S. M., Nevar T. N.: Cellulose acetate sulfate as a lyotropic liquid crystalline polyelectrolyte: Synthesis, properties, and application. International Journal of Polymer Science, 1, 831658/1831658/17 (2010). https://doi.org/10.1155/2010/831658

[36] Pitakpoolsil W., Hunsom M.: Adsorption of pollutants from biodiesel wastewater using chitosan flakes. Journal of the Taiwan Institute of Chemical Engineers, 44, 963-971 (2013).

https://doi.org/10.1016/j.jtice.2013.02.009

[37] Rattanapan C., Sawain A., Suksaroj T., Suksaroj C.: Enhanced efficiency of dissolved air flotation for biodiesel wastewater treatment by acidification and coagulation processes. Desalination, 280, 370-377 (2011).

https://doi.org/10.1016/j.desal.2011.07.018

[38] Ngamlerdpokin K., Kumjadpai S., Chatanon P., Tungmanee U., Chuenchuanchom S., Jaruwat P., Lertsathitphongs P., Hunsom M.: Remediation of biodiesel wastewater by chemical- and electro-coagulation: A comparative study. Journal of Environmental Management, 92, 2454-2460 (2011).

https://doi.org/10.1016/j.jenvman.2011.05.006 
[39] Matos C. T., Santos M., Nobre B. P., Gouveia L.: Nannochloropsis $s p$. biomass recovery by electro-coagulation for biodiesel and pigment production. Bioresource Technology, 134, 219-226 (2013).

https://doi.org/10.1016/j.biortech.2013.02.034

[40] Jaruwat P., Kongjao S., Hunsom M.: Management of biodiesel wastewater by the combined processes of chemical recovery and electrochemical treatment. Energy Conversion and Management, 51, 531-537 (2010). https://doi.org/10.1016/j.enconman.2009.10.018

[41] Sperling L. H.: Introduction to physical polymer science. Wiley, New York (1992).

[42] Knaus S., Bauer-Heim B.: Synthesis and properties of anionic cellulose ethers: Influence of functional groups and molecular weight on flowability of concrete. Carbohydrate Polymers, 53, 383-394 (2003).

https://doi.org/10.1016/S0144-8617(03)00106-1

[43] Delpech M. C., Coutinho F. M. B., Sousa K. G. M., Cruz R. C.: Viscometric study of urethanic prepolymers (in Portugese). Polímeros, 17, 294-298 (2007). https://doi.org/10.1590/S0104-14282007000400008

[44] Knothe G., Krahl J., Van Gerpen J.: The biodiesel handbook. AOCS Press, Champaign (2005).

[45] Vieira R. G. P., Filho G. R., de Assunção R. M. N., Meireles C. S., Vieira J. G., de Oliveira G. S.: Synthesis and characterization of methylcellulose from sugar cane bagasse cellulose. Carbohydrate Polymers, 67, 182-189 (2007).

https://doi.org/10.1016/j.carbpol.2006.05.007

[46] Nascimento B., Filho R. G., Frigoni E. S., Soares H. M., Meireles C. S., Cerqueira D. A., Valente A. J. M., de Albuquerque Carvalho R., de Assunção R. M. N., Motta L. A. C.: Application of cellulose sulfoacetate obtained from sugarcane bagasse as an additive in mortars. Jounal of Applied Polymer Science, 124, 510-517 (2012).

https://doi.org/10.1002/app.34881

[47] APHA $20^{\circ}$ ed., Method 1162: Standard methods for the examination of water and wastewater (1998).

[48] APHA $22^{\circ}$ ed., Method 2540: Standard methods for the examination of water and wastewater (2012).

[49] Lamb L. H., Decusati O. G.: Manufacturing process for quaternary ammonium tannate, a vegetable coagulating/flocculating agent. U.S. Patent 6478986 B1 (2002).

[50] Yi X. S., Shi W. X., Yu S. L., Sun N., Jin L. M., Wang S., Zhang B., Ma C., Sun L. P.: Comparative study of anion polyacrylamide (APAM) adsorption-related fouling of a PVDF UF membrane and a modified PVDF UF membrane. Desalination, 286, 254-262 (2012).

https://doi.org/10.1016/j.desal.2011.11.032
[51] Graham N., Gang F., Fowler G., Watts M.: Characterisation and coagulation performance of a tannin-based cationic polymer: A preliminary assessment. Colloids and Surfaces A: Physicochemical and Engineering Aspects, 327, 9-16 (2008).

https://doi.org/10.1016/j.colsurfa.2008.05.045

[52] Pal S., Mal D., Singh R. P.: Cationic starch: An effective flocculating agent. Carbohydrate Polymers, 59, 417423 (2005).

https://doi.org/10.1016/j.carbpol.2004.06.047

[53] Magalhães A. S. G., Almeida Neto M. P., Bezerra M. N., Ricardo N. M. P. S., Feitosa J. P. A.: Application of FTIR in the determination of acrylate content in poly(sodium acrylate-co-acrylamide) superabsorbent hydrogels. Química Nova, 35, 1464-1467 (2012).

https://doi.org/10.1590/S0100-40422012000700030

[54] Ravina L., Moramarco N.: Everything you want to know about coagulation \& flocculation. Zeta-Meter, Staunton, Virginia (1993).

[55] Lemanowicz M., Gierczycki A., Al-Rashed M. H.: Dualpolymer flocculation with unmodified and ultrasonically conditioned flocculant. Chemical Engineering and Processing: Process Intensification, 50, 128-138 (2011). https://doi.org/10.1016/j.cep.2010.12.006

[56] Fan A., Turro N. J., Somasundaran P.: A study of dual polymer flocculation. Colloids and Surfaces A: Physicochemical and Engineering Aspects, 162, 141-148 (2000). https://doi.org/10.1016/S0927-7757(99)00252-6

[57] Shak K. P. Y., Wu T. Y.: Synthesis and characterization of a plant-based seed gum via etherification for effective treatment of high-strength agro-industrial wastewater. Chemical Engineering Journal, 307, 928-938 (2017). https://doi.org/10.1016/j.cej.2016.08.045

[58] Somasundaran P., Das K. K., Yu X.: Selective flocculation. Current Opinion in Colloid and Interface Science, 1, 530-534 (1996).

https://doi.org/10.1016/S1359-0294(96)80123-3

[59] Shak K. P. Y., Wu T. Y.: Optimized use of alum together with unmodified Cassia obtusifolia seed gum as a coagulant aid in treatment of palm oil mill effluent under natural $\mathrm{pH}$ of wastewater. Industrial Crops and Products, 76, 1169-1178 (2015).

https://doi.org/10.1016/j.indcrop.2015.07.072

[60] Chavalparit O., Ongwandee M.: Optimizing electrocoagulation process for the treatment of biodiesel wastewater using response surface methodology. Journal of Environmental Sciences, 21, 1491-1496 (2009). https://doi.org/10.1016/S1001-0742(08)62445-6

[61] Xie Q-G., Taweepreda W., Musikavong C., Suksaroj C.: Separation of oily sludge and glycerol from biodiesel processing waste by coagulation. Songklanakarin Journal Science and Technology, 33, 699-703 (2011). 